\title{
Emergency Control Strategy Based on Multi-agent Theory under Blackout ${ }^{*}$
}

\author{
Bin Sun ${ }^{1}$, Ming Liu ${ }^{1}$, Luofang Zhu ${ }^{1}$, Nian Liu ${ }^{2}$, Xiaoyan Qiu ${ }^{2}$, Zhe Zhuang ${ }^{2}$ \\ ${ }^{1}$ Guizhou Power Grid Corporation of Dispatch Control Center, Guiyang, Guizhou, China \\ ${ }^{2}$ School of Electrical Engineering and Information Sichuan University, Chengdu, China \\ Email: zhuangzhe3000@vip.qq.com,cd_qxy@sina.com
}

Received March, 2013

\begin{abstract}
The multi-agent theory is introduced and applied in the way to strike the control amount of emergency control according to stability margin, based on which an emergency control strategy of the power system is presented. The multi-agent control structure which is put forward in this article has three layers: system agent, areal agent and local agents. System agent sends controlling execution signal to the load-local agent according to the position and the amount of load shedding upload from areal agent; The areal agent judges whether the power system is stable by monitoring and analyzing the maximum relative power angle. In the condition of instability, determines the position of load-shedding, and the optimal amount of load-shedding according to the stability margin based on the corrected transient energy function, upload control amount to system agent; local-generator agent is mainly used for real-time monitoring the power angle of generator sets and uploading it to the areal agency, local-loads agent control load by receiving the control signal from system agent. Simulations on IEEE39 system show that the proposed control strategy improves the system stability.
\end{abstract}

Keywords: Multi-agent; Corrected Transient Energy Function; Emergency Control; Stability Margin

\section{Introduction}

With the development of economy, the growing of the load demand, the increase of grid scale, the continuous development of the regional interconnection and longdistance transmission of electricity markets, the grid is long-running at the limit state, the stability margin is getting smaller and smaller. When the grid is affected by the large disturbance, it may cause grid instability, and longtime power off, even network splitting [1-4]. Emergency control can reduced the extent of the damage to a minimum after the grid is affected by the large disturbance, so, it is an important measure to maintain system stability [5-8].

In the field of artificial intelligence, Multi-Agent has good characters of autonomy, reactivity, initiative and social. It is contributing to emergency control to change from "Off-line pre-decision-making, real-time match." to "Real-time decision-making, real-time execution". Literature [9] applies the Multi-agent technology to the power system black start. Reference [10] proposed the method changed from centralized management to distributed coordinated management through the Multi-

\footnotetext{
${ }^{*}$ The project supported by GuiZhou Power Grid Corporation (12H0594), Technology Project of Science \& Technology Department of Sichuan Province (No.2011GZ0036)
}

Agent system approach. Article [11] shows the Multicriteria hierarchical emergency control system is conducive to independent autonomous effect between the layers.

In the literature, multi-agent theory is introduced into the way based on the stability margin to strike control amount of the emergency control, proposes emergency control strategy based on multi-agent technology[12-15], the multi-agent control organizational structure has three layers: system agent, areal agent and local agents.

\section{Multi-agent Control Organizational Structure}

The multi-agent control organizational structure has three layers: system agent, areal agent and local agents. The primary responsibility of system agency is receiving the data of load shedding position and the amount of load shedding and to issue a control signal to local load Agent; the main responsibility of areal agent is to received and processed the data quickly and accurately, and to determine load shedding position and the amount of load shedding; the primary responsibility of local agency is to real-time detecting the state of each generator group, to transmute real-time testing data is to the regional agency, and to control the load. The multi-agent control organizational structure is as shown in Figure 1. 


\section{Emergency Control Strategy}

In the normal state the electromagnetic torque of the generator output keep balanced with the mechanical torque of the prime mover Input, after large interference, Generator set power becomes imbalance, it changes the generator power, the speed and the relative angle between the rotors. If the generator relative motion gradually increases, the generator will be out of Step, even the system will become unstable. So, the stability of the power system is closely related to generator angle.

Because the transient stability of the system usually has relationship with maximum relative angle $\delta_{\max }$ between the generator rotor, areal agency uses the maximum relative angle as the standard to determine whether the system is instability, detects the operation state of the power system according to the angle data local generator agent upload, and strikes the optimum amount of load shedding by stability margin based on the modified energy function. Control strategy shown in Figure 2.

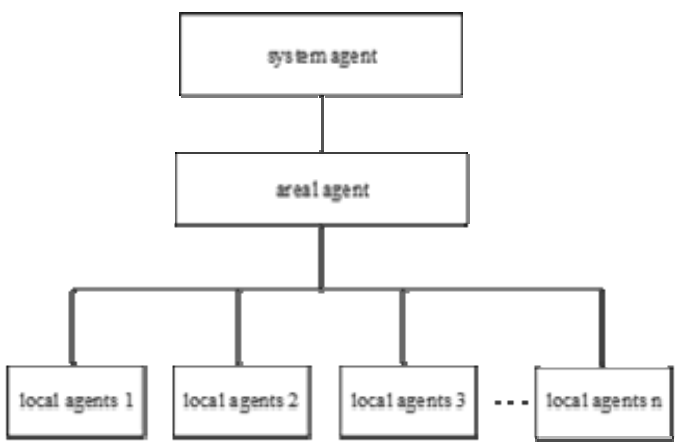

Figure 1. The multi-agent control organizational structure.

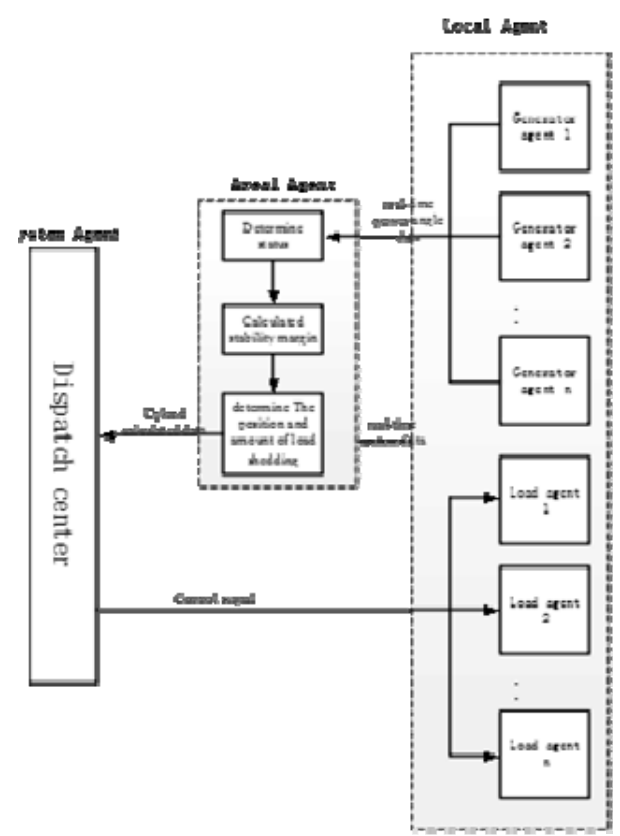

Figure 2. Multi-agent control strategy.

\subsection{System Stability Analysis}

According to maximum relative angle $\delta_{\max }$ between the generator rotor, In this paper, using the maximum relative swing angle method determines system stability. Defining transient stability constraint conditions is:

$$
J\left(\delta\left(T_{e}\right), u\right)=\rho^{2}-\sum \beta \max _{\forall i, j}\left\{\left[\delta_{i}\left(T_{e}\right)-\delta_{i}\left(T_{e}\right)\right]^{2}\right\} \geq 0
$$

$T_{e}$ is the integral end moments, $\rho$ is transient stability angle threshold. In the actual system, it can be selected $180-270$ based on experience. $\beta$ is pending multiplier. It can be determined in accordance with the following provisions:

$$
\begin{aligned}
& \text { When } \max _{\forall i, j}\left\{\left[\delta_{i}\left(T_{e}\right)-\delta_{i}\left(T_{e}\right)\right]^{2}\right\} \leq \rho^{2}, \beta=0 \\
& \text { When } \max _{\forall i, j}\left\{\left[\delta_{i}\left(T_{e}\right)-\delta_{i}\left(T_{e}\right)\right]^{2}\right\} \geq \rho^{2}, \beta=1
\end{aligned}
$$

$J\left(\delta\left(T_{e}\right), u\right)$ can be regarded as a characterization system transient stability indicators.

For the performance index function, define new simulation termination value $\varepsilon$, this value determines the end time $T_{m}$, determine it according to the following rules.

$$
\begin{aligned}
& \text { If, } \max _{\forall i, j \forall t \in\left[T_{0}, T_{e}\right]}\left\{\left[\delta_{i}\left(T_{e}\right)-\delta_{j}\left(T_{e}\right)\right]^{2}\right\} \geq \varepsilon^{2} \\
& \text { when } \max _{\forall i, j \forall t \in\left[T_{0}, T_{e}\right]}\left\{\left[\delta_{i}\left(T_{e}\right)-\delta_{j}\left(T_{e}\right)\right]^{2}\right\}
\end{aligned}
$$

across termination value $\varepsilon^{2}$ at the first time, the first moment is taken as $T_{m}$.

If,

$$
\rho^{2} \leq \max _{\forall i, j \forall t \in\left[T_{0}, T_{e}\right]}\left\{\left[\delta_{i}\left(T_{e}\right)-\delta_{j}\left(T_{e}\right)\right]^{2}\right\} \leq \varepsilon^{2}
$$

take it as $T_{m}=T_{e}$

\subsection{The Optimum Load Shedding Amount Based on Modified Energy Function}

After System is disturbed, For System leading unit A and the remaining sets $\mathrm{B}$, consider the equations of motion of the rotor.

$$
\begin{aligned}
\omega_{A} & =\frac{1}{M_{A}} \sum_{i \in A}\left(P_{m i}-P_{e i}-\frac{M_{i}}{M_{T}} P_{C O I}\right) \\
& =\frac{1}{M_{A}}\left(P_{m A}-P_{e A}\right)-\frac{1}{M_{T}} P_{C O I} \\
\omega_{B} & =\frac{1}{M_{B}} \sum_{i \in A}\left(P_{m i}-P_{e i}-\frac{M_{i}}{M_{T}} P_{C O I}\right) \\
& =\frac{1}{M_{B}}\left(P_{m B}-P_{e B}\right)-\frac{1}{M_{T}} P_{C O I}
\end{aligned}
$$

The dynamic equation between generators $\mathrm{A}$ and $\mathrm{B}$ is: 


$$
\begin{aligned}
M_{e q} \frac{d \omega}{d t} & =\frac{M_{e q}}{M_{A}}\left(P_{m A}-P_{e A}\right)-\frac{M_{e q}}{M_{B}}\left(P_{m B}-P_{e B}\right) \\
& \equiv P_{A B}
\end{aligned}
$$

And $\omega=\omega_{A}-\omega_{B}$, multiply $\omega$ at both side, consider the relationship $\theta=\omega$.

$$
\begin{aligned}
& \frac{1}{2} M_{e q} \omega_{t}^{2}+\int_{t^{\text {sep }}}^{t}-P_{A B} \frac{d \theta}{d t} \\
= & \frac{1}{2} M_{e q} \omega_{t^{a e}}^{2}+\int_{t^{\text {sep }}}^{t}-P_{A B} \frac{d \theta}{d t} \\
= & \text { const }
\end{aligned}
$$

Defining corrected transient energy function is

$$
\begin{aligned}
V & \equiv V_{K E}+V_{P E} \\
& =\frac{1}{2} M_{e q} \omega_{t}^{2}+\int_{\theta^{\text {sep }}}^{\theta}-P_{A B} d \theta
\end{aligned}
$$

A sudden change in the operational status of the system did not happen next time, the correction energy function of the system is conserved.

According to the definition of the energy margin, the energy difference between the critical energy and the energy of system at the fault clearing time is energy margin.

$$
\begin{gathered}
\Delta V=V^{c r}-V^{c l} \\
\operatorname{CTEM}\left(T_{r 2}\right)=\operatorname{CTPE}(B) \\
-\left(\operatorname{CTPE}\left(t_{c l}\right)+\left(\operatorname{CTKE}\left(t_{c l}\right)-\operatorname{CTKE}_{\min }\left(T_{r 2}\right)\right)\right)
\end{gathered}
$$

The first term is critical energy, the second term is the energy at the fault clearing time. For stable fault trajectory, General system trajectory will pass through zero, so $C T K E_{\text {min }}\left(T_{r 2}\right)=0$

$$
\begin{aligned}
& \operatorname{CTEM}\left(T_{r 2}\right) \\
= & \operatorname{CTPE}(B)-\left(\operatorname{CTPE}\left(t_{c l}\right)+\operatorname{CTKE}\left(t_{c l}\right)\right)
\end{aligned}
$$

And

$$
\begin{aligned}
& \operatorname{CTEM}\left(T_{r 2}\right) \\
= & \Delta \operatorname{CTPE}\left(t_{c l}\right)-\operatorname{CTKE}\left(t_{c l}\right)
\end{aligned}
$$

The $\triangle C T P E\left(t_{c l}\right)$ mean the ability that the system absorb effective CTKE after the fault is cut at the moment of $t_{c l}$. This energy can be expressed as:

$$
\begin{aligned}
& \operatorname{CTEM}\left(t_{c l}\right) \\
= & -\sum_{i=1}^{n} \frac{1}{2}\left(\alpha_{i}\left(\theta\left(t_{c l}+\Delta t\right)\right)+\alpha_{i}\left(\theta\left(t_{c l}\right)\right)\right)\left(\theta\left(t_{c l}+\Delta t\right)-\theta\left(t_{c l}\right)\right) \\
& +\left(\operatorname{CTKE}\left(t_{c l}+\Delta t\right)-C T K E_{\min }\left(T_{r 1}\right)\right)
\end{aligned}
$$

The

$$
-\sum_{i=1}^{n} \frac{1}{2}\left(\alpha_{i}\left(\theta\left(t_{c l}+\Delta t\right)\right)+\alpha_{i}\left(\theta\left(t_{c l}\right)\right)\right)\left(\theta\left(t_{c l}+\Delta t\right)-\theta\left(t_{c l}\right)\right)
$$

means the incremental of system transient correction energy at the moment of $t_{c l}$ to $t_{c l}+\Delta t$,

$$
\left(C T K E\left(t_{c l}+\Delta t\right)-C T K E_{\min }\left(T_{r 1}\right)\right)
$$

means the system absorb effective CTKE after the fault is cut at the moment of $t_{c l}+\Delta t$. For the unstable trajectory, $\operatorname{CTKE}_{\min }\left(T_{r 1}\right)$ is not zero. So, the stable trajectory stability margin expressed as:

$$
\begin{aligned}
& \operatorname{CTEM}\left(T_{r 2}\right) \\
= & -\sum_{i=1}^{n} \frac{1}{2}\left(\alpha_{i}\left(\theta\left(t_{c l}+\Delta t\right)\right)+\alpha_{i}\left(\theta\left(t_{c l}\right)\right)\right)\left(\theta\left(t_{c l}+\Delta t\right)-\theta\left(t_{c l}\right)\right) \\
& +\left(\operatorname{CTKE}\left(t_{c l}+\Delta t\right)-C T K E_{\min }\left(T_{r 1}\right)\right)-\operatorname{CTKE}\left(t_{c l}\right)
\end{aligned}
$$

In fact, it uses the partly flat characteristic of correction potential interface. If consider $\Delta t$ is very small, the transient correction potential of both $e_{1}$ and $B$ is almost equal. The utility improved template completely avoiding pseudo fault points. For the stable failure closes to instability, we can strike a fault stability margin just after two systems simulation.

The modified potential energy function to overcome the nonlinear of traditional hybrid method of the stability margin curve, the curve of the system stability margin is smooth at different resection amount after stabilization measures action.

Optimal amount of load shedding

Based on the characteristics of the energy margin with the amount of load shedding curve, we can get stability margin and $\operatorname{CTEF}\left(P_{1}\right)$ according to fault simulation and energy function analysis at two kind amount of load shedding $P_{0}$ and $P_{1}$. Strike the active load shedding capacity limit which meet system transient stability by using the energy margin interpolation law.

$$
P_{c r}=P_{1}+\frac{\operatorname{CTEM}\left(P_{1}\right) \Delta P}{\operatorname{CTEM}\left(P_{0}\right)-\operatorname{CTEM}\left(P_{1}\right)}
$$

Only when the system occur instability failure, do the emergency control measures be used, therefore, according to the margin curve linear features in the unstable region, the amount of load resection $P_{c r}$ can be stroked by unstable margin interpolation of different resection amount of $P_{0}$ and $P_{1}$.

\section{Analysis of Examples}

In order to verify the effectiveness of the proposed method, simulate on IEEE39 system, System as shown in Figure 3.

Assume that the fault is a three-phase fault, fault location is selected at generator bus or load bus bar. Simulation results as shown in Table $\mathbf{1 .}$

From the simulation results, the control measures can ensure the stability of the system, the multi-agency theory in power system emergency control has a positive effect on system stability. 


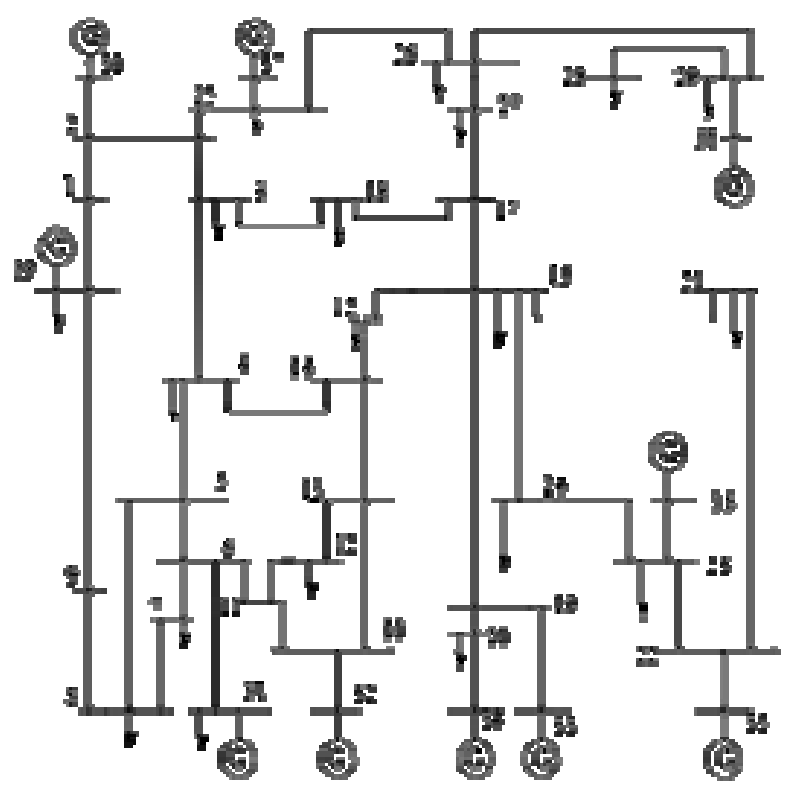

Figure 3. 10, 39-bus system diagram.

Table 1 result of load shedding scheme in IEEE39 system.

\begin{tabular}{|c|c|c|c|c|c|c|}
\hline $\begin{array}{l}\text { Fault } \\
\text { location }\end{array}$ & $\begin{array}{l}\text { Resection } \\
\text { line }\end{array}$ & $\begin{array}{c}\text { Critical clearing } \\
\text { time } / \mathrm{s}\end{array}$ & $\begin{array}{l}\text { Actual fault clearing } \\
\text { time } / \mathrm{s}\end{array}$ & $\begin{array}{l}\text { Shutdown } \\
\text { generator }\end{array}$ & $\begin{array}{l}\text { Load shedding program } \\
\text { (Load node number, } \\
\text { The amount of load shedding) }\end{array}$ & $\begin{array}{l}\text { results of the } \\
\text { control measures }\end{array}$ \\
\hline 3 & $3-4$ & $0.27 \sim 0.28$ & 0.29 & 37 & $18 ;-1.0324-j 0.2765$ & Stable \\
\hline 6 & $5-6$ & $0.16 \sim 0.17$ & 0.24 & 31 & $4 ; \quad-0.6244-j 0.2856$ & Stable \\
\hline 10 & $10-13$ & $0.21 \sim 0.22$ & 0.24 & 32,39 & $12 ; \quad-0.4332-\mathrm{j} 0.1004$ & Stable \\
\hline 15 & $14-15$ & $0.19 \sim 0.22$ & 0.23 & 32,37 & $15 ;-0.7420-\mathrm{j} 0.2519$ & Stable \\
\hline 17 & $17-18$ & $0.22 \sim 0.23$ & 0.33 & 37 & $18 ;-1.2654-j 0.5750$ & Stable \\
\hline 23 & $22-23$ & $0.24 \sim 0.25$ & 0.28 & 36 & $22 ; \quad-0.8861-j 0.4021$ & Stable \\
\hline
\end{tabular}

\section{Conclusions}

In the literature, multi-agent theory is introduced into the way based on the stability margin to strike control amount of the emergency control, proposes emergency control strategy based on multi-agent technology, the multi-agent control organizational structure has three layers. It is achieved systems state data real-time interaction, show multi-Agent has good characters of autonomy, reactivity, initiative and social. It is contributing to emergency control to change from "Off-line pre-decision-making, real-time match." to "Real-time decisionmaking, real-time execution".

Simulations on IEEE39 system show that the proposed control strategy improves the system stability.

\section{REFERENCES}

[1] D. Ruiz-Vega and M. Pavella, "A Comprehensive Approach to Transient Stability Control Part I-Near Optimal Preventive Control, Part II—Open Loop Emergency
Control,” IEEE Transactions on Power System, 2003,

Vol. 18, No. 4, pp. 1446-1460.

doi:10.1109/TPWRS.2003.818708

[2] D. Gan, R. J. Thomas and R. D. Zimmerman, Stability-constrained Optimal Power Flow," IEEE Transactions on Power Systems, Vol. 15, No. 2, 2000, pp. 535-540.doi:10.1109/59.867137

[3] X. Y. Li and L. Li, "Survey of the Emergency Control in Power System," Automation of Electric Power Systems, Vol. 24, No. 9, 2000, pp. 5-11.

[4] L. Li, Z. Yan, Z. X. Wang, et al., "Emergency Control Strategies Based on the Model of the A-S-C," Automation of Electric Power Systems, Vol. 33, No. 5, 2009, pp. 7-11.

[5] Z. Chen, W. J. Du, H. F. Wang, et al., "Framework of Multi-agent System in Post-emergency Voltage Stability Control,” Automation of Electric Power Systems, Vol. 30, No. 12, 2006, pp. 33-37.

[6] M. J. Zhang, L. X. Cao, J. W. Li, et al., "Multi-agent System for Voltage/VAR Optimization Considering Multi-regional Power System,” Automation of Electric 
Power Systems, Vol. 28, No. 17, 2004, pp. 33-37.

[7] A. Ian and M. A. Pai. Hiskens, "Trajectory Sensitivity Analysis of Hybrid System," IEEE Transactions on Power System, Vol. 47, No. 2, 2002, pp. 204-220.

[8] B. Tony and M. A. Pai. Nguyen, "Dynamic Security-Constrained Rescheduling of Power Systems Using Trajectory Sensitivities," IEEE Transactions on Power System, Vol. 18, No. 2, 2003, pp. 848-854. doi:10.1109/TPWRS.2003.811002

[9] T. Nagata and H. Sasaki, "A Multi-agent Approach to Power System Restoration," IEEE Transactions on Power Systems, Vol. 17, No. 2, 2002, pp. 457-462. doi:10.1109/TPWRS.2002.1007918

[10] C. S. Wang and X. Y. Yu, "Distributed Coordinative Emergency Control Based on Multi-agent System," Power System Technology, Vol. 28, No. 3, 2004, pp. 1-5.

[11] L. F. Li, Z. M. Wang, J. L. Yu, et al., "Hierarchical Sys- tem with Multi-criterion for Voltage Emergency Control Based on MAS," Electric Power Automation Equipment, Vol. 26, No. 5, 2006, pp. 5-10.

[12] Z. D. Bi, J. Q. Wang, et al., “A Fast Shedding Algorithm Based On Integral Sensitivity,” Power System Technology, Vol. 26, No. 8, 2002, pp. 4-7, 43.

[13] Z. H. Feng and S. X. Zhou, "Determination of Voltage Collapse Areas in Large Scale Power System,” Proceedings of the CSEE, Vol. 17, No. 3, 1997, pp. 21-26.

[14] J. Q. Sun, D. Z. Fang and T. S. Chung, "Optimal Power Flow with Transient Stability Constraints,” Proceedings of the CSEE, Vol. 25, No. 12, 2005, pp. 12-17.

[15] Daniel Ruiz2Vega and Mania Pavella, "A Comprehensive Approach to Transient Stability Control Part I-N Ear Optimal Preventive Control Part II-Open Loop Emergency Control," IEEE Transactions on Power Systems, Vol. 18, No. 4, 2003, pp. 1446-1460. doi:10.1109/TPWRS.2003.818708 